\title{
Gray Baby Syndrome
}

National Cancer Institute

\section{Source}

National Cancer Institute. Gray Baby Syndrome. NCI Thesaurus. Code C113421.

A disorder observed in a newborn who was exposed to chloramphenicol. Manifestations include hypotension, cyanosis, cardiovascular collapse and/or death. 